\title{
ملامح الهوية والاغتراب للنحت في الوطن العربي
}

أستاذ مساعد نحت كلية الفنون الجميلة جامعة البصرة العرق 2018 م

محسن علي حسين

ملخص البحث

يتعرض هذا البحث لدراســة مفردتين مهمتين ( الهوية و الاغتراب ) اللذين لهما عملهما المنفرد والمشــترك في

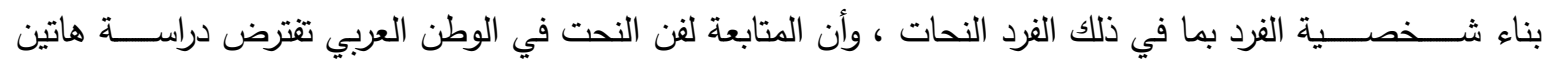

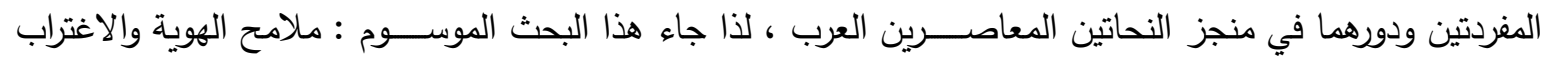

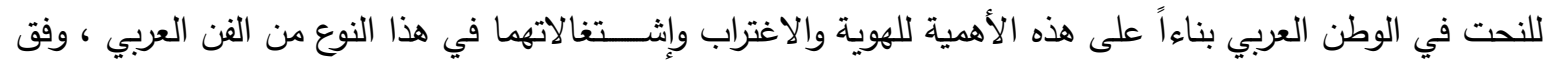

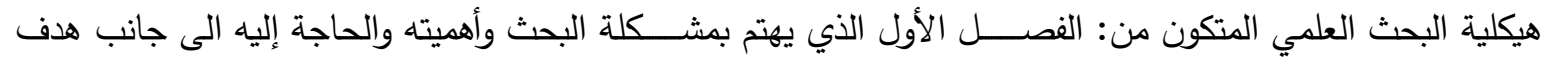

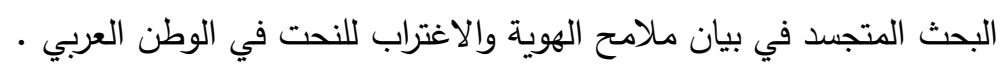

أما الفصل الثاني والمعنون بالإطار النظري يحوي : ( الهوية ، وأنواعها ) و (الهوية العربية مقوماتها وآليات تحقيقها فنياً) و (الاغتراب وأنواعه - البوادر الأولى للهوية والاغتراب في النحت العربي المعاصر ) في حين سيكون الفصل الثالث مخصصاً

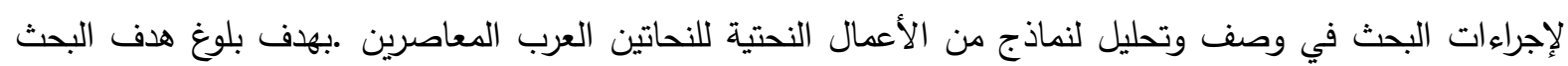
وتحقيق نتائجه التي خصص الفصل الرابع لعرضها. الإطار المنهل الأول

مشكلة البحث :

تثكل الهوية مطلب مهم يسعى لتحقيقه الفرد / الفنان في فعله الحياتي المختلف بما فيه منجزه الفني ، ويتخذ عدة الطرق المختلفة والوسائل المتعددة في سبيل تحقيق هذا المطلب ( الهوية ) ـ وكذا هو الحال لدى النحات العبي المعاصر فئه

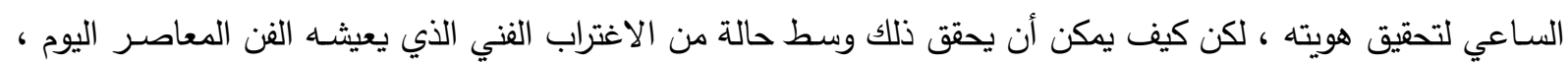

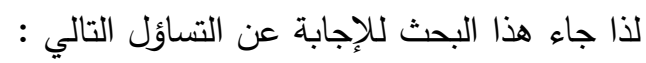
ماهي ملامح الهوية والاغتراب في النحت العربي المعاصر ؟ لهاء

أهمية البحث والحاجة إليه : تتطلق أهمية هذا البحث من حيث : 1. تعرضه للنحت العربي المعاصر في التعرف على مايحمله من ملامح الهوية والاغتراب . 2.

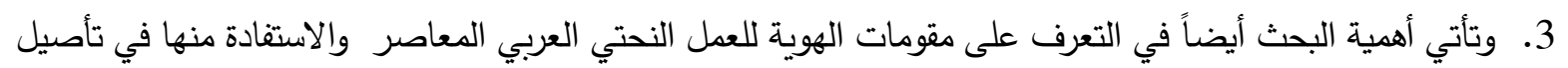
تلك الهوية حاضراً ومستقبلاً . 4. دعم الجوانب المعرفية المتحققة من حيث كونه مصدر يسد الحاجة الماسة للنحت العربي المعاصر و ما يتعلق به

$$
\text { ضمن البحث العلمي الفني. }
$$


يهدف البحث الى بيان ملامح الهوية والاغتراب للنحت المعاصر في الوطن العربي.

منهج البحث :

يعتمد البحث على المنهج الوصفي التحليلي كونه من أقرب المناهج التي يمكن عن طريقه تحقيق هدف البحث . حلود البحث :

يتحدد البحث في دراســة الأعمال النحتية العربية المعاصــرة وبيان ملامح الهوية والاغتراب فيها ، تلك الأعمال التي

تتوع مابين الأعمال المعرضية الصغيرة و النصبية الكبيرة . الفصل الثاني

الإطار النظري

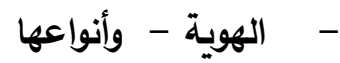

تأخذ الصورة التعريفية لأي شيء أو أي فرد أو أي جماعة بما يحمله من ملامح مميزة تفرز تلك الصورة عن سواها

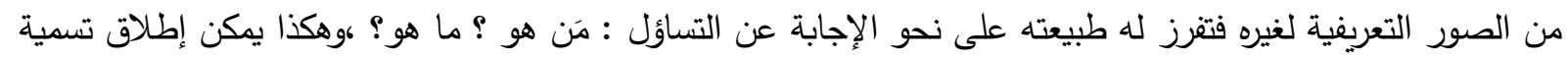
الهوية على وفق الصورة التي تفرزها هذه الإجابة ، وهذا المفهوم(الهوية) يعبر عن ((نسق المعايير التي يعرف بها الفهرد

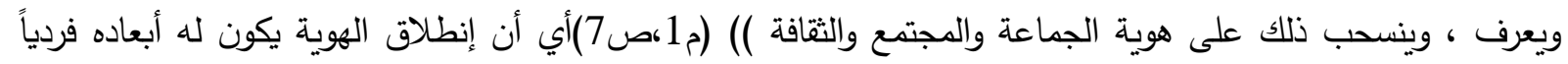

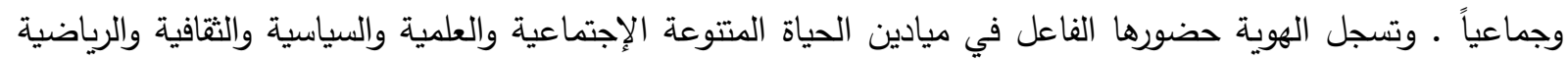
والفنية ، ولا يقتصر حضور الهوية على أساس الحضور الآني فحسب ، بل بل لها عمقها الحضوري التأريخي وتأخذ صورة تعريفية للمجتمات والثعوب على أنها أي الهوية ((تصف الثعوب بأنها متقدمة أو متخلفة أو في طريق النهو النمو وإذا كانت

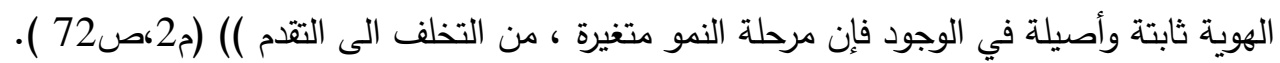

إن الهوية بهذا المفهوم تعزز من صورة الانتماء للفرد وسط الجماعة المجتمعية ، والوطنية والقومية ، بل وحتى أن

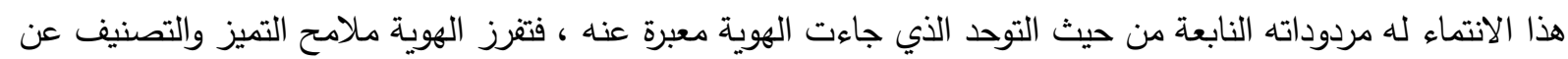
الآخر ومن خلال ذلك تعرّف الهوية هنا على أنها ((الثفرة التي يمكن للفرد عن طريقها أن يعرف نفسه في علاقتته بالجماعة التهاه

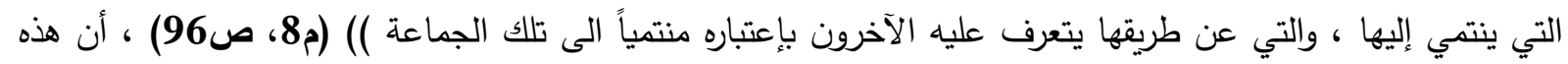

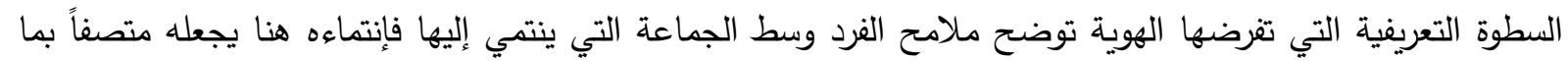

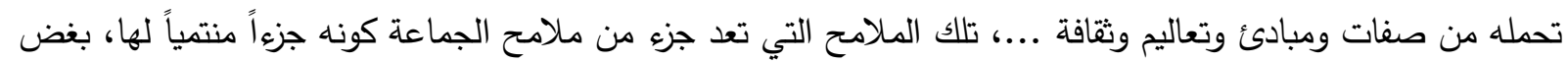

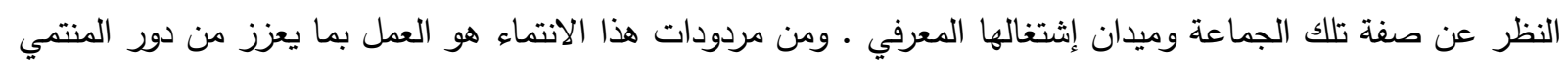

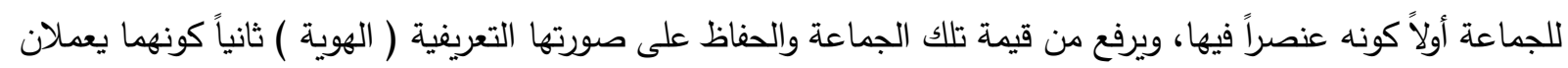

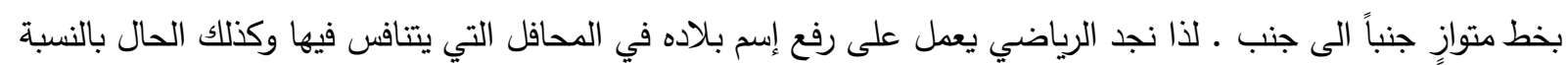

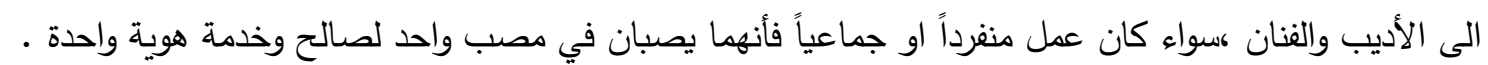

لذا يمكن أن نحدد نوعين من الهويات هما : 
وهي الهوية التي تصف الثخص أو الثئ على أنه هو هو بما هو كائن دون غيره الآخر ، وهنا تكون الهوية تعبير

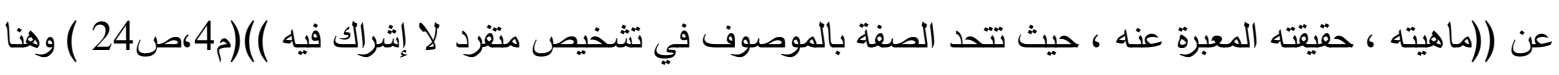

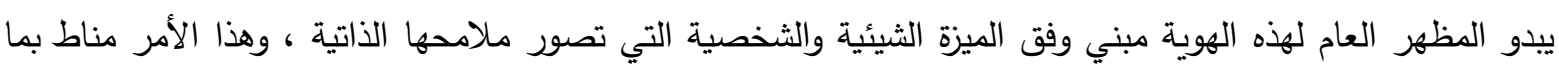

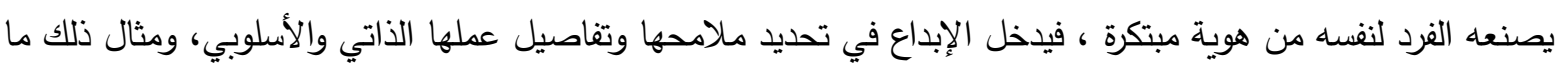

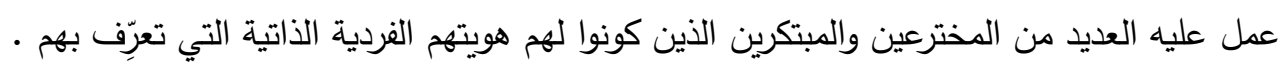

2. 2 الهوية الجماعية : عملهية

وهي الهوية المنبثقة من حيث الوجود الجماعية فتتصف أفرادها بصفة التعميم أو التعميم ، وهنا تدخل عدّة أمور في

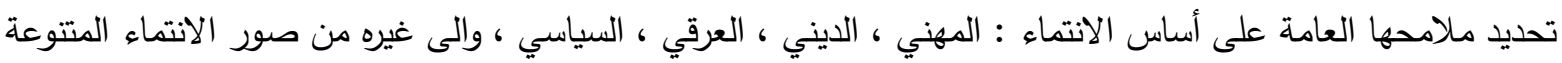

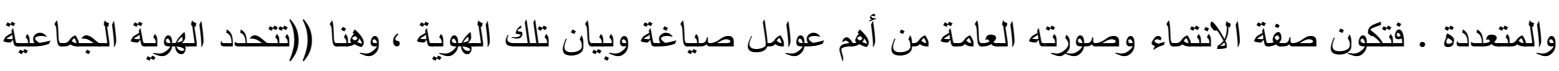
في إطار تتظيم متكامل ، وتمثل وحدة كلية تثتمل على عناصر متقاربة ومتكاملة لتشكل عبر ذلك كله حقيقة اجتماعية )(م) 1، ص22) ، و إن هذا التقسيم تقسيم تتوعي وليس تقسيم تعددي ، حيث اشتغال التتوع وفق وحدة العناصر ، بينما

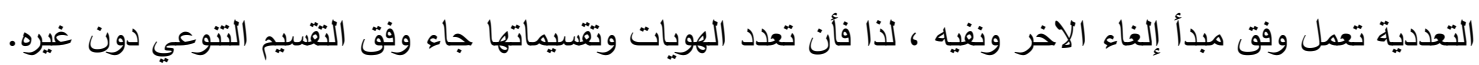

\section{- - الهوية العربية مقوماتها وآليات تحقيقها}

يفرز الحضور العربي هوية موحدة ومشتركة في ميادين الحياة المختلفة بغض النظر عن ذلك الحضور تحت مسىى

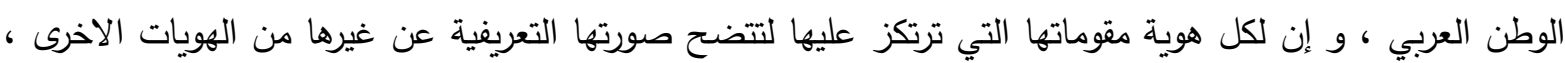

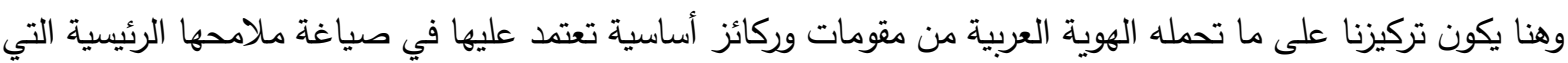

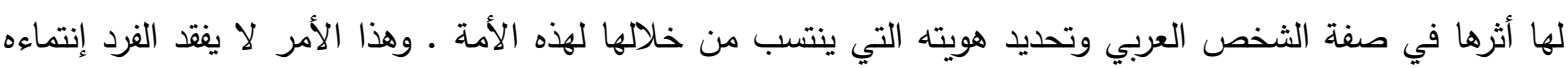

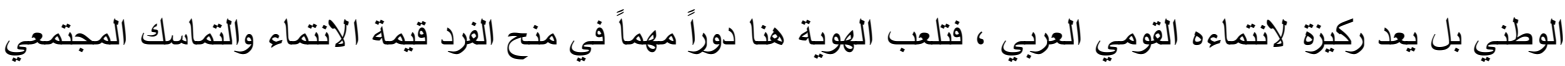

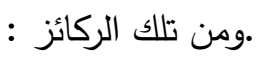

اللغة : محور مهم في بيان ملامح الهوية العربية وعنصر فاعل في توطيد حالة الانتماء لهذه الهوية ، واللغة العربية مرتكز أساسي في الهوية العربية والتي عن طريقها تتوحد صور التفاهم والتعبير بصفة مشتركة ، فجاءت معبرة عن حالة الانتماء

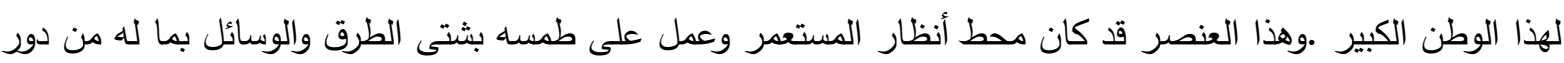

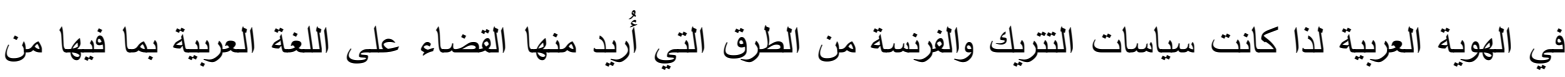

البيئة : تلتوع البيئات الحاوية لميدان الاشتغال التي يمارسها الأفراد ، فتتصف بعنوان ذلك الفعل الاشتغالي ، وتأخذ صورتها منه فتكون بيئة عمل وبيئة دراسة وبيئة سياسية وغيرها من البيئات الأخرى .فتوحيد صورة الانتماء البيئي يسقط بظلالهه على الئي

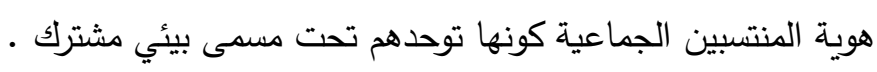

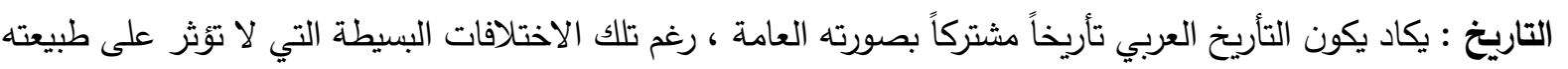

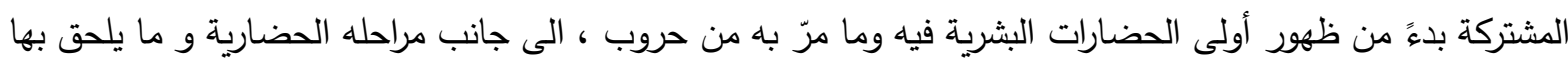

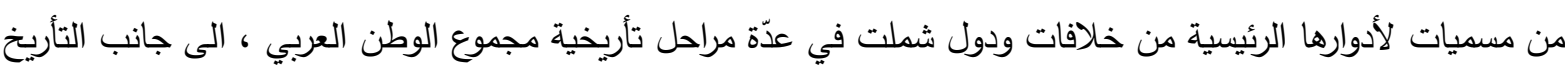

المشترك للتخلص من المستعمر ، والى غيرها من صور تأريخية تعزز من صور الانتماء لهذا الوطن الكبير تأريخياً.

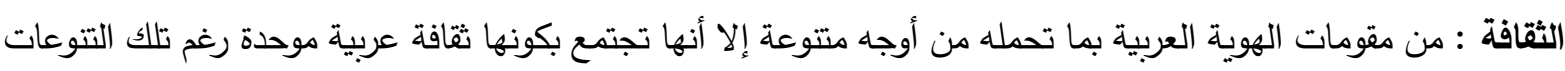
التي أعطتها صفة الخصوصية المحلية ، حتى أن النشاطات الثقافية المشتركة عملت على توحيد هوية الانتماء العربي بما فيها من ملتقيات ومهرجانات واتحادات وجمعيات عربية متتوعة ـ تعمل بجملتها للحفاظ على المظهر الثقافي العربي

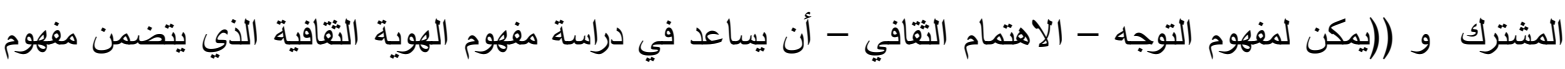


الجهح المركزي الخاص بالهوية )(م 1، ص35) ، الى جانب ذلك ثمة مقومات أخرى لا تقل أهمية عن هذه المقومات مثل الدين والمصير المشترك ...، والتي بجملتها تعمل على تعزيز الانتماء بصورة هوية عربية مشترك الملامح والصفات . .

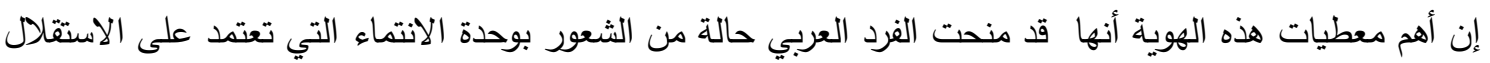

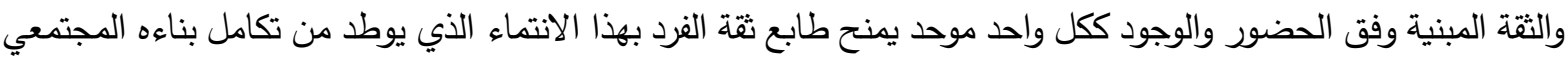
العام

- ـ الموروث : يشكل الموروث بكل عناصره من المقومات التي لها دور كبير في صياغة الهوية ، والوطن العربي حافل بالموروث البيئي والثعبي والحضاري ، الممتدة بعدره الزمني الطويل حيث عمق حضارتي العراق ومصر والحضارات

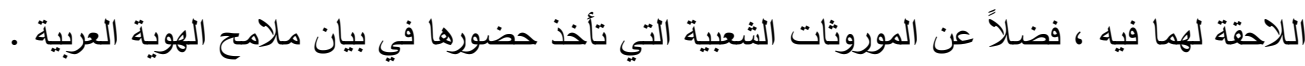

\section{الاغتراب}

تختلف التعريفات التي تبين مفهوم الاغتراب العام تبعاً للحجال الذي ينظر إليه من خلاله هذا الدفهوم بحيث يظهر

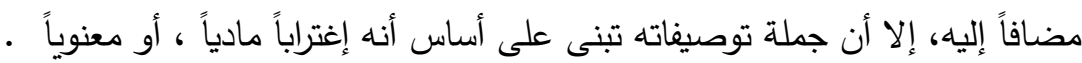

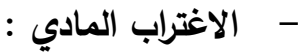

هو ما يتجسد بإبتعاد الفرد عن موطنه وتجاوز حدوده المكانية بحيث يصبح منقطعاً عنه ـ وله عدة أسباب منها ما

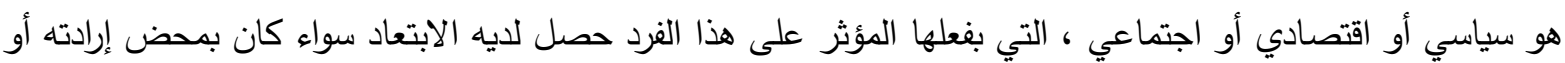
مجبراً عليه ، فالنتيجة واحدة هي حصول الاغتراب عن وطنه مكانياً ((الحالة التي ينفصل بها الفرد عن مجتمعاه وثقافته ، نتيجة تعقيدات الحياة اليومية ، وعند حدوث هذا الانفصال فأن الامر سيفضي الى حالة من النفور ومن ثم عدم الاكتراث

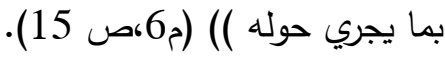

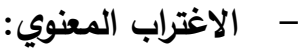
وهنا يكون الاغتراب متعلقاً بالجانب المعنوي لدى الفرد ، فلم يعد الابتعاد المكان هو المقصود، بل حتى وإن كان

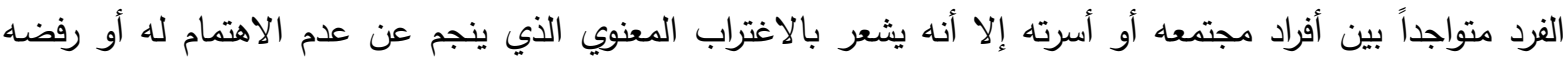

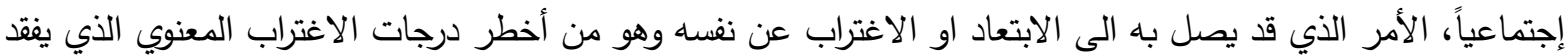
فيه الفرد الصلة بذاته مما يؤدي به الى حالة من الانعزال والقطيعة وقد يؤدي به الى مخاطر كبيرة تصل الى حد الانتحار،

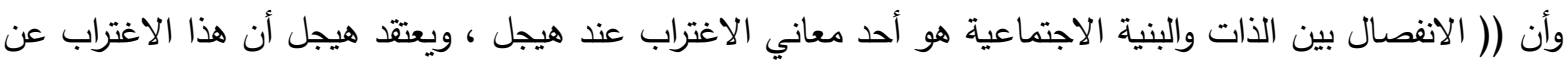

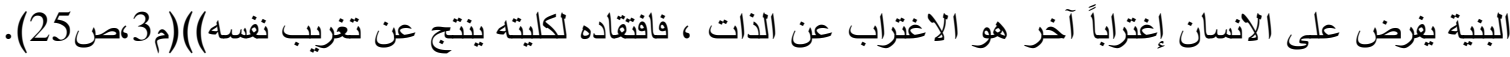
ومن ذلك يعد الاغتراب حالة من حالات الانفصال التي تحدث للفرد مما تحيد به عن طبيعة واقعه المعاش بكل ما فيه من المظاهر الترابطية التي تمثل حلقات التواصل فيما بينه وبين مجتمعه الأول ، فيغدو هذا المجتمع من أهم المسببات المؤدي الى الاغتراب ، والذي يؤدي به الحالة من الاغتراب النفسي، وهي ((الحالة التي ينفصل بها الفرد عن

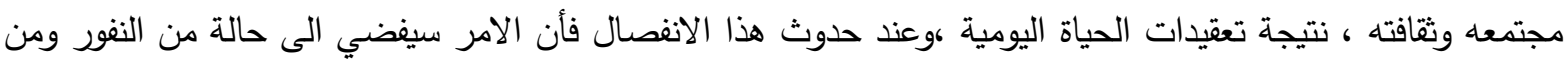
ثم عدم الاكتراث بما يجري حوله )) (م6،ص 15). وهذا الانفصال يجعله في نوع من الغربة التي توجب عليه إيجاد بيئة

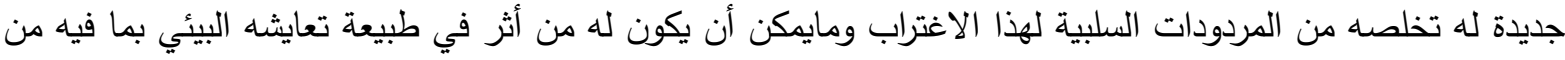

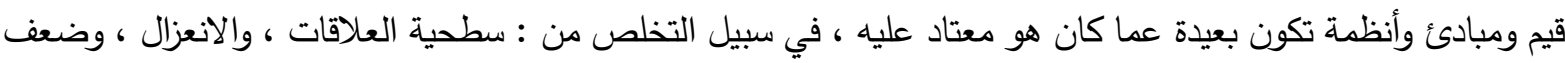
التواصل الاجتماعي والثقافي وغيرها من الأمور التي تجعله في حالة من الاكتآب والانطواء وفقدان الانتماء ، لذاء كان ونان ولازال

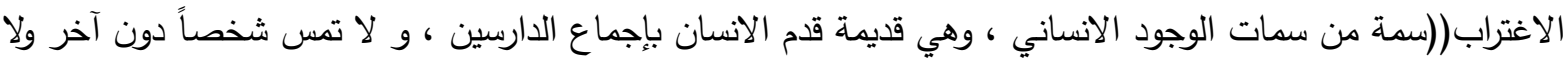

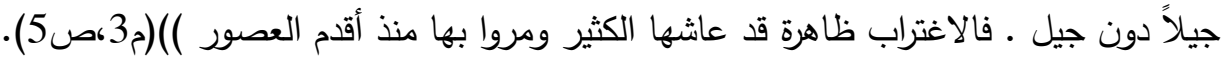


لاثك أن حدوث الاغتراب يمكن أن تلحق في جانب معين لاى الفرد دون جوانب أخرى كأن يكون لديه اغتراب :

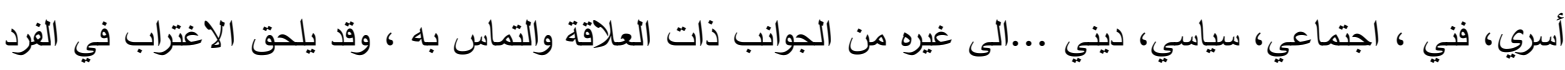

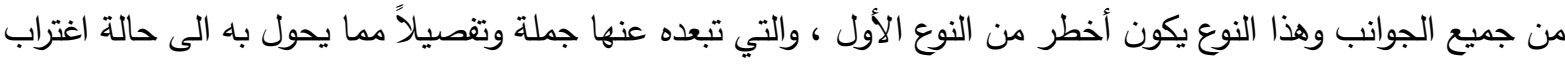

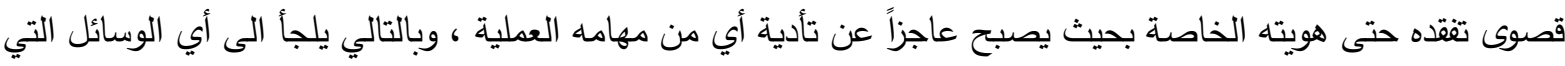

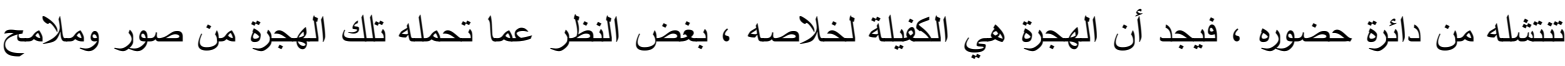

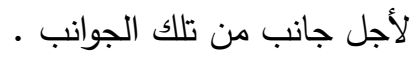

ومن خلال ذلك الاغتراب والانتماء الجديد يتحتم على الفرد التأقلم مع محيطه الجديد بكل مايحمله من ملامح وعوامل

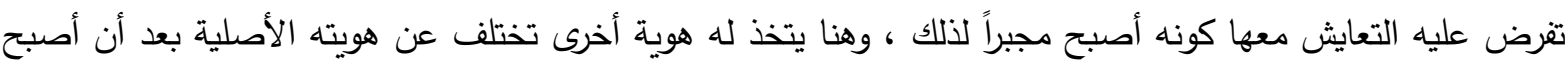

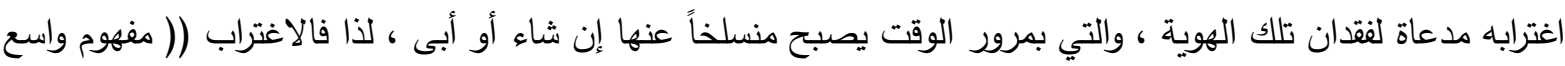

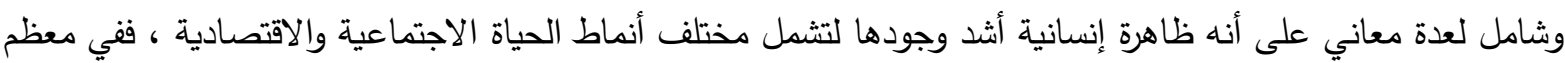
الثقافات المعاصرة تتزايد مشاعر الاغتراب وتتحدد نتيجة لطبيعة العصر الذي يعيشه الإنسان عصر التناقضات معاً)) (م7،

\section{- - البوادر الأولى للهوية والاغتراب في النحت العربي المعاصر}

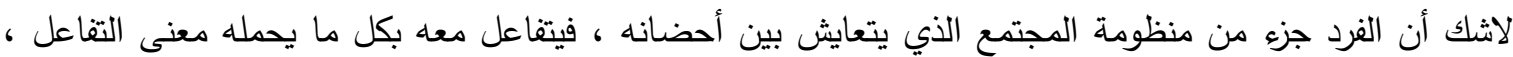

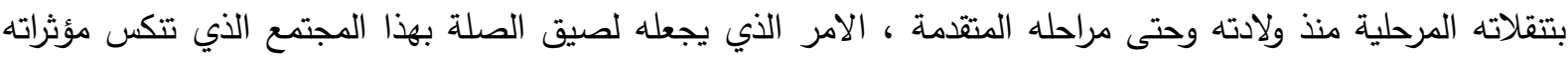

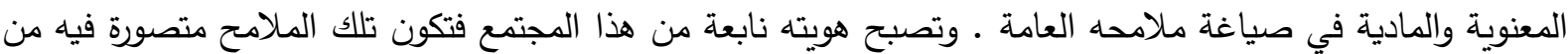

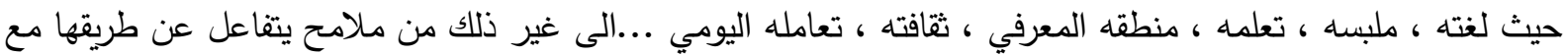

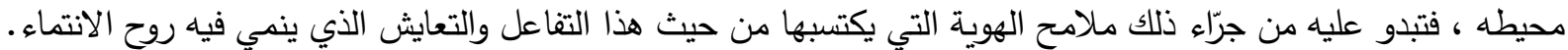
والفنان يشكل حلقة من حلقات وأصناف المجتمع وتنطبق عليه تلك الملامح التي تمنحه هويته التي يعكسها في منجزه الفني

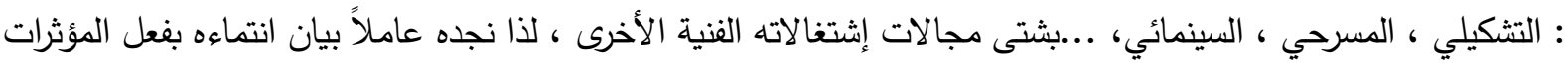

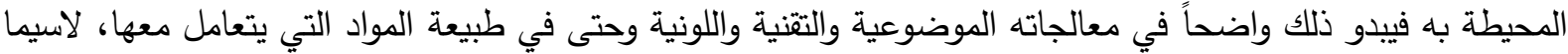
وانه يستعرض حضور هويته بما فيها من ملامح تميزه عن الاخر ، فنجد تأثرات البيئة والموروث من ابرز تلكاتك الملامح كونها

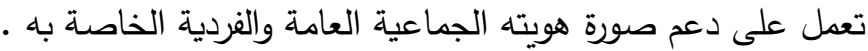

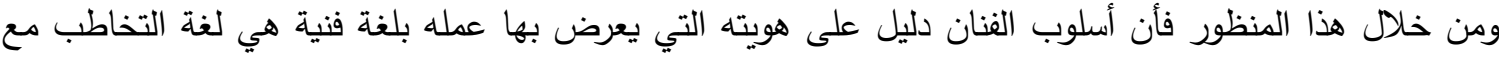
الآخر بما يحمله ذلك العمل من بنى فكرية يبتغي الفنان طرحها الى حيز الوجود سواء كان ذلكانك الطرح الفني جماعياً (معارض

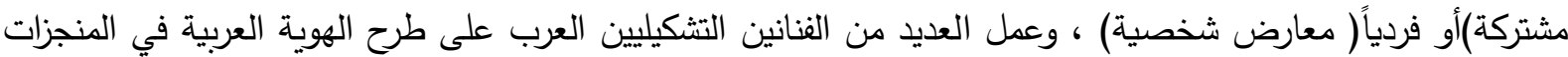

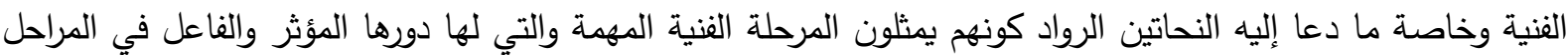

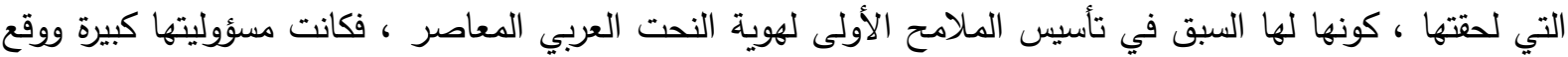

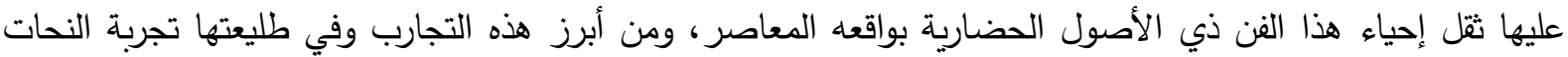

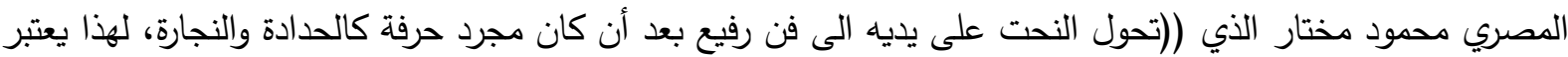

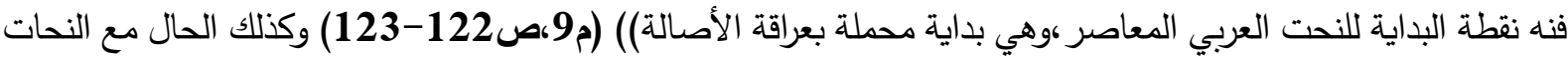


العراقي جواد سليم ، وهما المؤسسان والرائدان الأوليان لفن النحت المعاصر في مصر والعراق ، ولهما دور كبير في الجانب

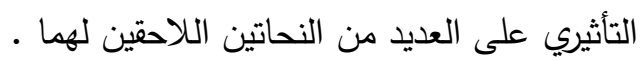

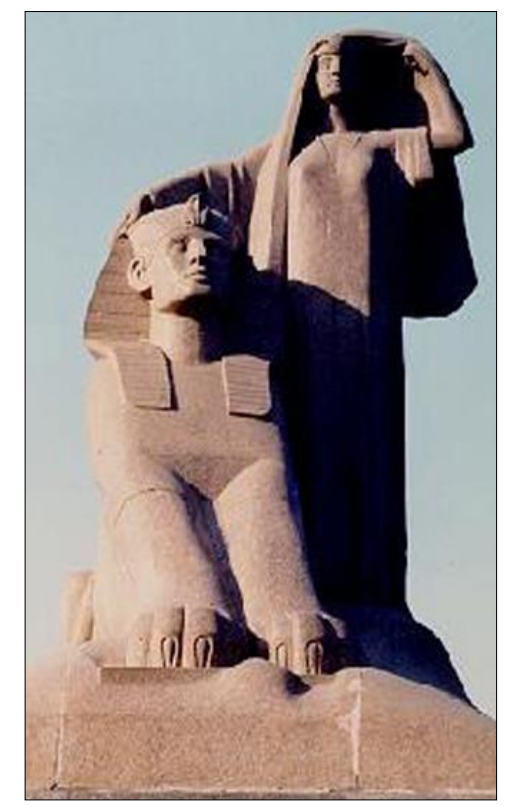

شكل 1

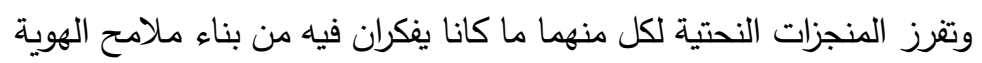

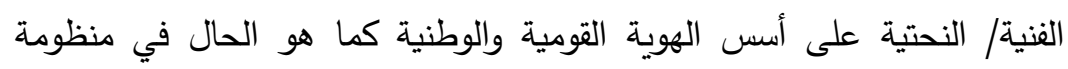
المعطيات الفكرية والرمزية التي بثها محمود مختار في عمله (نهضة مصر ) شكل الهله

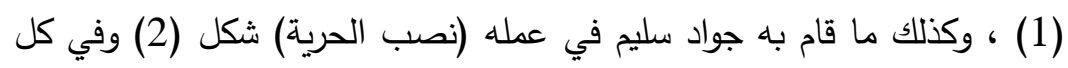

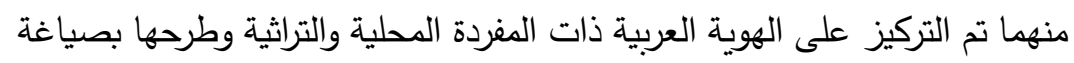
فنية بلغتها الأسلوبية العالمية ، ولم يقتصر دورهما في هذا الجانب بل كان لهما

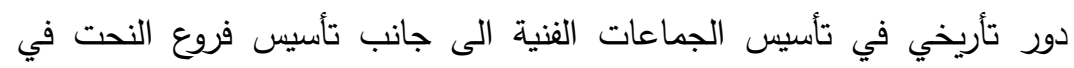
المؤسسات الفنية بإتجاهاتها الفنية المتنوعة وتقنيات مختلفة التي أخذ منها النيات النحاتون العرب بسرعة ((بكل ما فيها من حراك وإضافات وهلوسات وصراعات طاولت لغنة لغنة

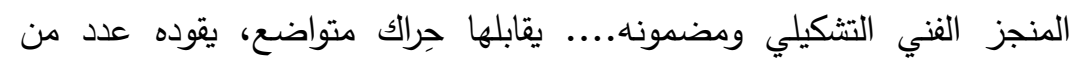

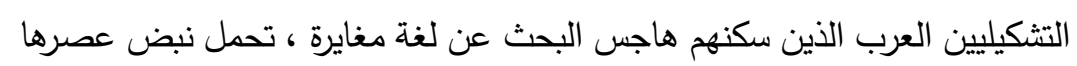

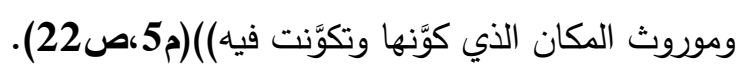

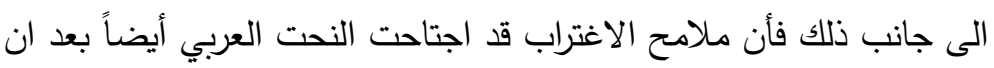
غادر النحات العربي موطنه نحو بلاد الغربة في المهجر ، بفعل عدة عوامل منها ماهو سياسي ومنها ما هو اقتصادي ومنها ماهو لغرض الدراسة ومن ثم الاستقرار هناك بعيداً عن موطنه الأول وتطبعه بأطباع

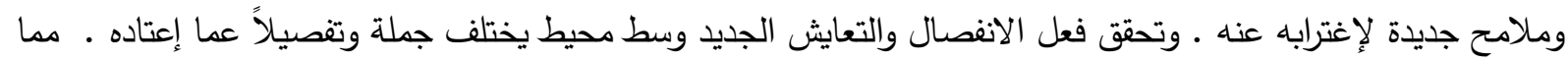
أنعكس ذلك على منجزاته الفنية التي ظهرت في ملامح لهويته الجديدة هوية الاغتراب ، بأساليب ومواضيع ومواد جديدة

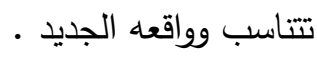

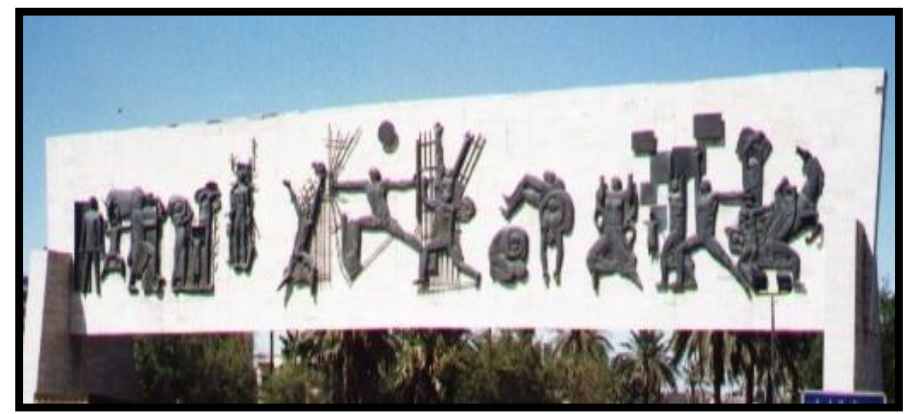

شكل 2
و لا يقتصر أمر الاغتراب وملامحه عن

اغتراب النحات خارج بلده فحسب ، بل بل من المعكن

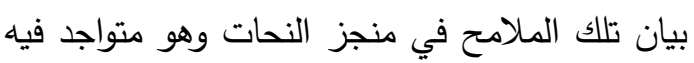
كونه يعيش حالة يمكن أن ندعوها بالاغتراب الداخلي

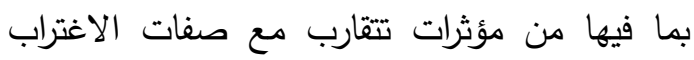

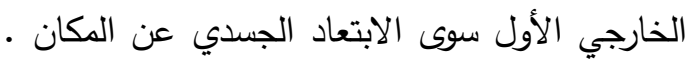
وإن الاتجاهين أعلاه يصوران الملامح التي تثرز التعاد حضور النحت العربي ومجالات إثتغالاته الجمالية

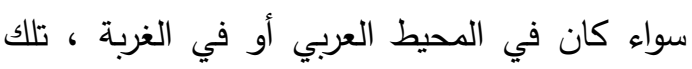
الملامح التي تتقاد الى الظروف المحيطة بالنحات وما يمكن أن تسقطه من مردودات على الفعل الفني النحتي الذي يمارسه في المكانين • 


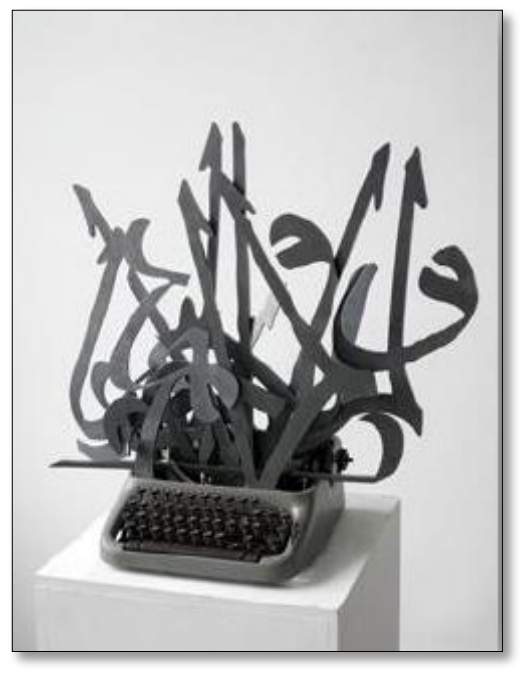

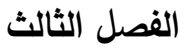 \\ تحليل نماذج من النحت العربي المعاصر

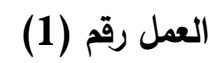 \\ حروف وطابعة النحات منير الفاطمي (المغرب)
}

يعرض النحات العربي المغربي منير الفاطمي عمله النحتي هذا مستخدماً

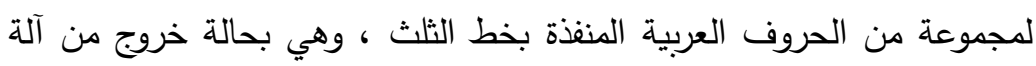

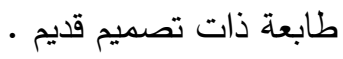

إن هذا العمل النحتي يخرج به النحات نحو الجمع مابين الفعل النحتي لما

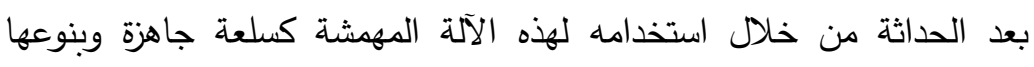

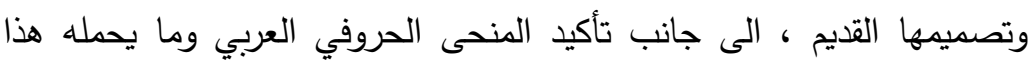
الحرف من بيان وعرض لهوية النحت العربي ، والتأكيد كذلك على أصالة وعمق هذا البيان بإستخدامه لخط الثلث الذي يعد التيد من أرقى وأعرق الخطوط العربية .

إنها ممازجة تعامل معها النحات بصيغة المنطق النحتي الذي تلاحمت فيه الهوية العربية الأصيلة وفنون ما بعد الحداثة ، مما يفتح المجال للمتلقي العربي والعالمي بتحسسه للذة الجمالية من تلقيه وقراءته لهذا العمل النحتي ، إنه طرح

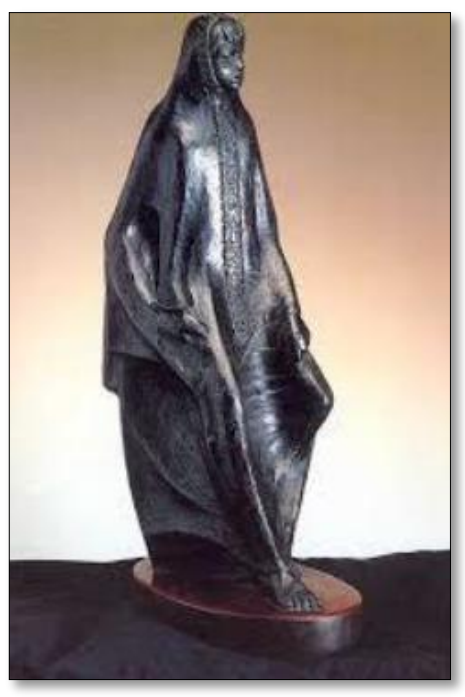

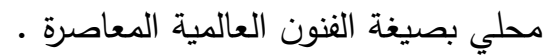

\title{
العمل رقم (2) فـــتاة النحات عيسى صقر (الكويت)
}

يوضح العمل النحتي المجسم والمصنوع من مادة البرونز فتاة ترتدي الزي

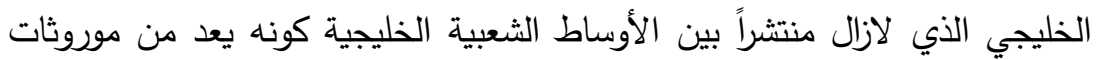

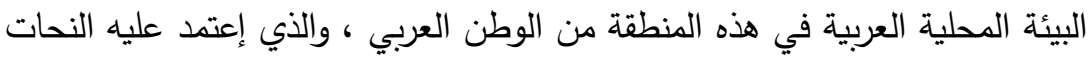
في صياغة وتوضيح خصوصية عمله البيئية العربية الخليجية ، كون الزي من الملامح المميزة لهوية أي مجتمع أو بلد من البلدان موصدئ

فظهرت الفتاة وهي بوضع حركي يعم جملة التكوين النحتي بدءً من حركة الرأس

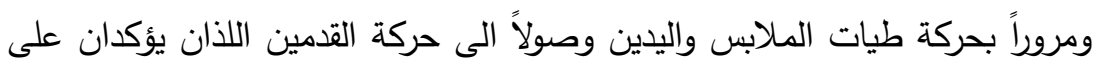
إستمرار الحركة للفتاة

إن الزي الذي ترتديه الفتاة هنا لم يعيق النحات في بيان الملامح النحتية لمجموع التكوين كونه يغطي الجسم بأكمله

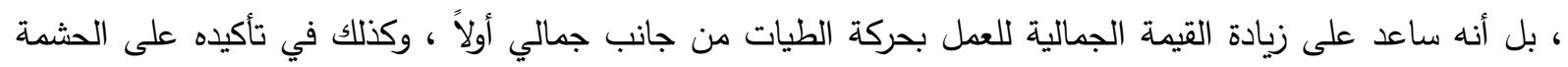

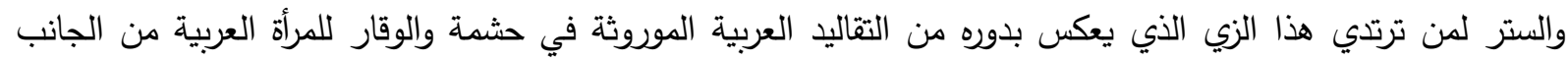
الدلالي والتعبيري ثانياً 


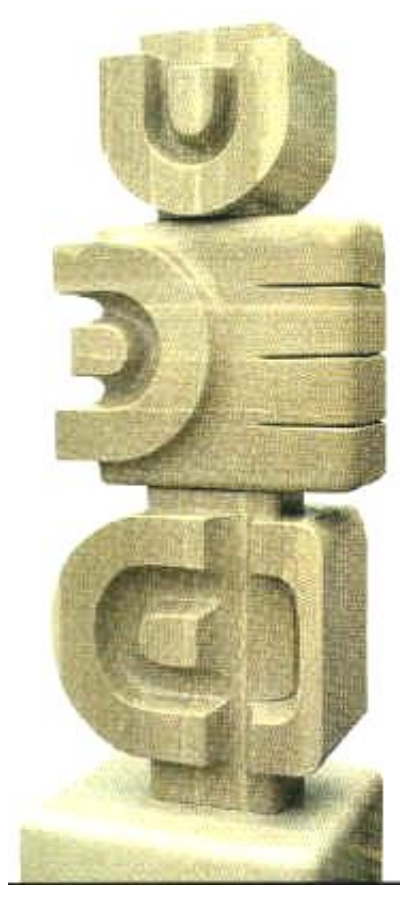

العمل رقم (3) حروف النحاتة منى السعودي (الأردن) مجموعة من الحروف العربية نفذتها النحاتة الأردنية منى السعودي بقطعة من الادنالئه المرمر

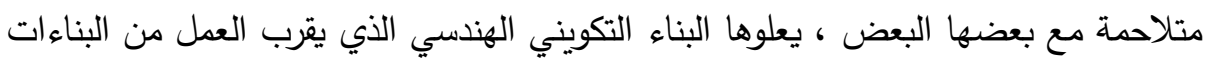

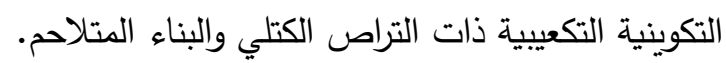

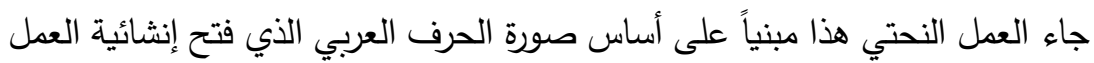

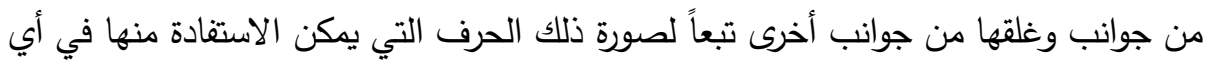

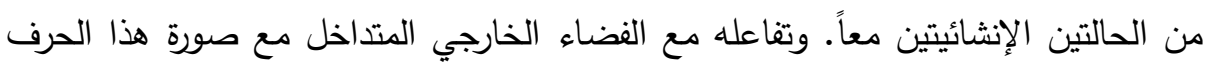

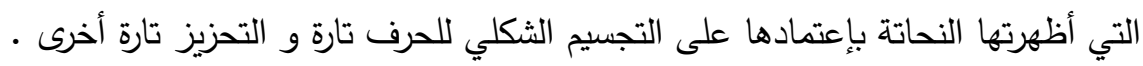
القيمة الجمالية لهذا العمل تبدو من خلال توظيف الحرف العربي في عمل من دون مكملات تكوينية وبصورة هندسية تثعر المتلقي بأهمية هذا الحرف ومايمكن أن يحققه في

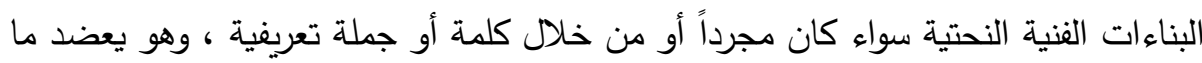
عمل عليه الفنانون الحروفيون الذين أكدوا على قيمة الحرف العربي ومايمكن أن يحققه في مجال الفن التثكيلي بما فيه فن النحت من جانب ، ومن جانب آخر ما يمكن أن يحققه هذا

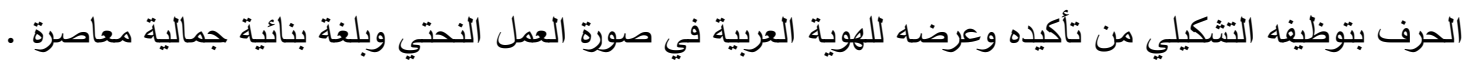

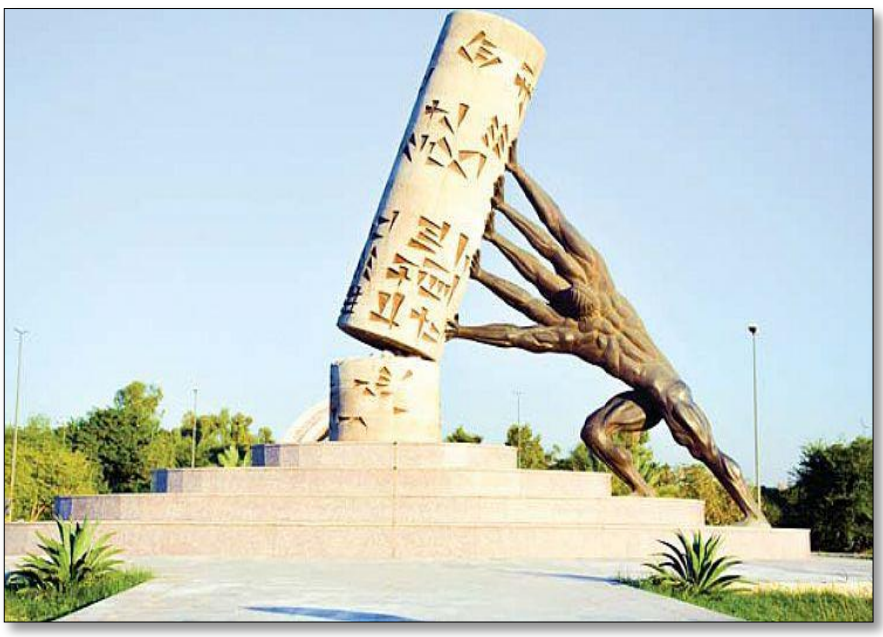

العمل رقم (4) نصب إنقاذ العراق النحات محمد غني حكمت

(العراق)

يتخذ النحات محمد غني حكمت من موضوعة

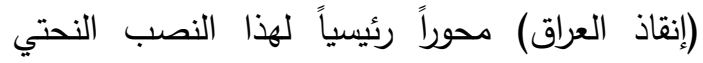

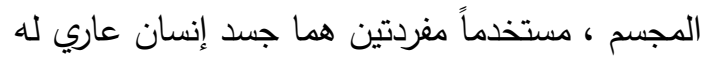

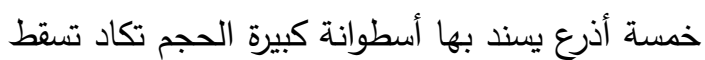
بعد أن كسرت من جزها السفلي ، وقد نحتت عليها بشكل غائر كتابات مسمارية فظهرت على هيئة ختم إسطواني والذي

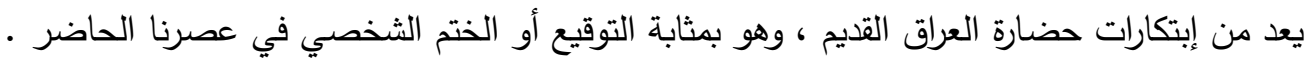
إن النحات هنا قد عمل على إستلهام هذه المفردة الموروثة وقد أدخلها في تمثيل رمزي للعراق وإنقاذه من السقوط بمجموع هذه الأذرع التي تلاحمت في رجل واحد كتمثيل رمزي لوحدة المجتمع العراقي وتلاحم طوائفه المتتوعة ، وإظهاره بشكل عارٍ خالِ من أي تدخلات خارج محيطه الوطني ، محافظاً على العراق من السقوط وإعلاء شأنه . أي أن العمل بين حالة من التلاحم مابين المعطى التعبيري الرمزي للعمل مع البيان التمثيلي النحتي لمفردتيه - الرجل والختم الاسطواني - بحاضر جسدي و إستلهام للموروث الذي يثكل جزء مهم وفاعل في بيان وتصوير الهوية المحلية للنحات العراقي ، وجزء من شخصيته الممثلة والمميزة له بين أقرانه . 
هذا النصب بمحتواه البياني النحتي واستلهامه التأريخي قد جعل المتلقي المحلي على إرتباط معه كونه إستحضر الموروث بروحية العصر الحديث وما يعانيه البلد من مخاطر ومحاولة صدها بتوحد صفوفه المجتمعية جميعاً ، إنه روحية

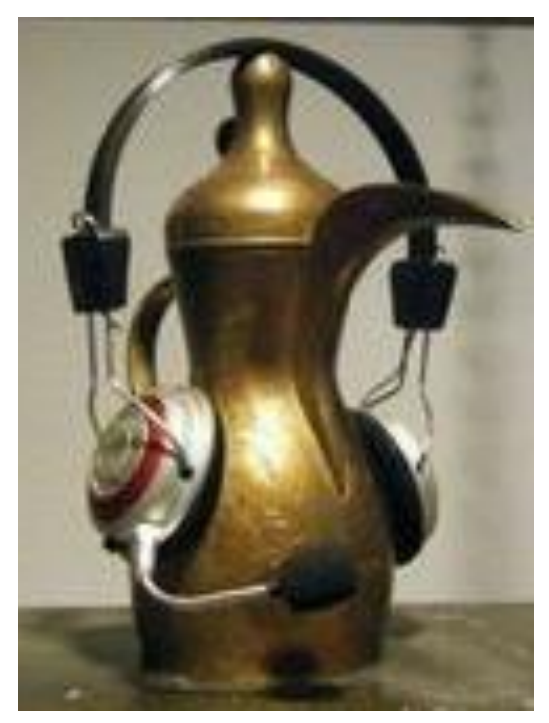
الهوية المحلية للعراق بقطبيها الماضي والحاضر ل

العمل رقم (5) الدلة النحات صديق واصل

(السعودية)

يبنى هذا العمل النحتي على مفردة إجتماعية عربية وهي (الدلة) بكونها

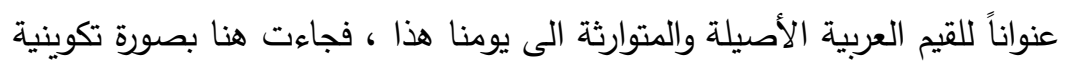
مجتمعة مع جهاز السمع (Headphone) بثكل تركيبي • إن العمل منفتح التأويل بفعل دلالاته المتعددة والتي جاءت بفعل المفردتين المستخدمتين في العمل وما يمكن أن يفرزان من إشارات ورموز دلالية يستثفها المتلقي

بما يتحلى به من خزين معرفي للدفردتين • فالدلة مفردة ورمز عربي أصيل لها عمقها التأريخي في المجتمع العربي ، ولها من المعاني المتتوعة التي تدل على دمثي

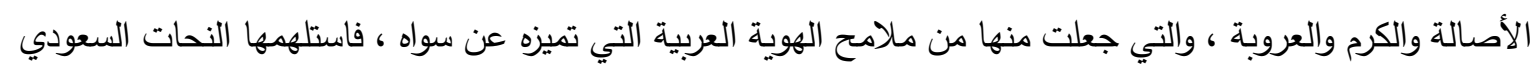

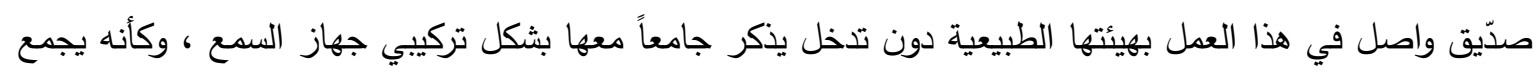

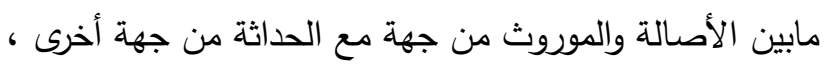

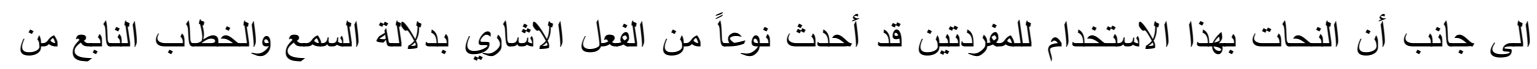

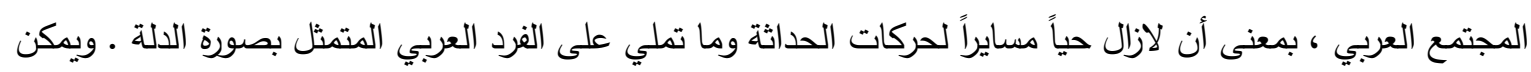
أن نجد في العمل تعددية المعنى بانفتاحه التأويلي التي تبين فعله في الرفع من مكانة القيم العربية الأصيلة وتمثلها

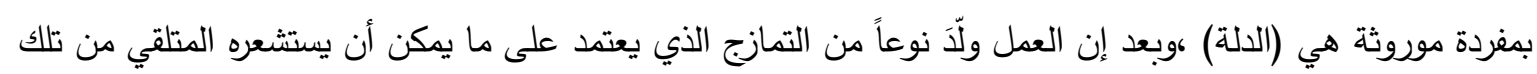
الصور الدلالية بتطبيقات الفعل التأويلي عليها بذات الفهر والتفسير الذي يبنى على خلفية المتلقي للقيم العربية الأصيلة

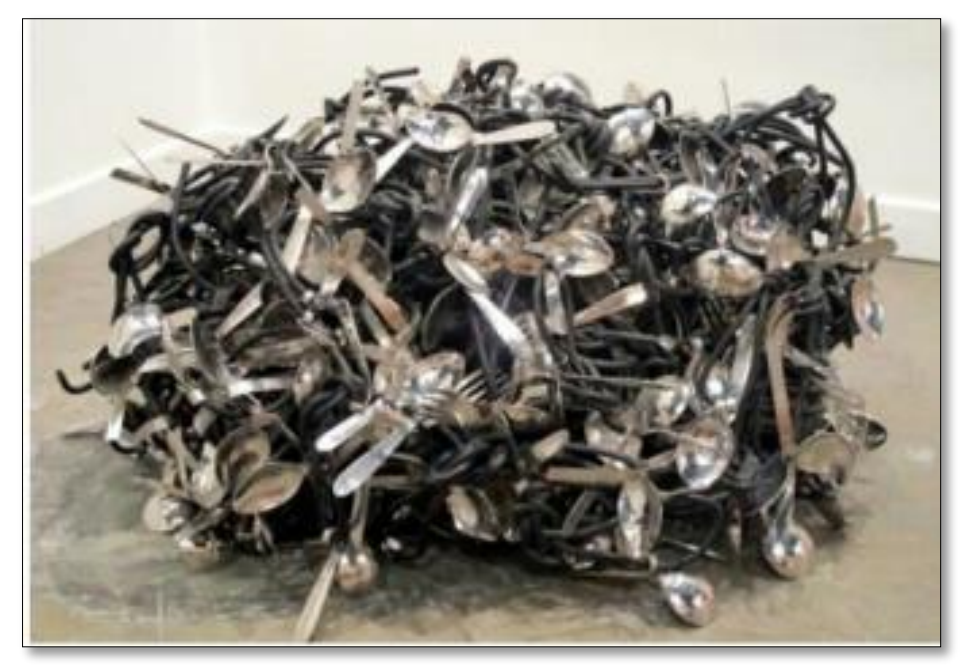
وكيف أصبحت ملامح تواجدها بين ثنايا المجتمع العربي كهوية تعريفية عربية .

(6) العمل رقم

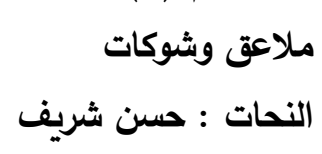

(الإمارات)

يعرض النحات حسن شريف في عمله هذا واحداً من الاتجاهات النحتية المعاصرة في فنون ما بعد الحداثة والتي تفرز شكلها من خلال إستخدام المواد التالفة بثتى أنواعها، وهنا يستخدم النحات مجموعة كبيرة من الملاعق لئنق 
والثوكات جامعها بصورة مجموعة كبيرة الحجم وعارضاً إياها وسط قاعة العرض ، بثكل يحدث لدى المتلقي نوعاً الدهثة

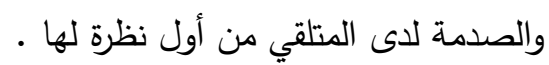
وبجنبة تأويلية للعمل نجد فيه إثارات دلالية لطبيعة المجتمع العربي الاستهلاكي بعد أن إستخدم النحات لصورة واحدة

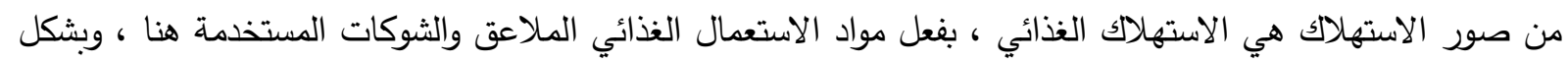

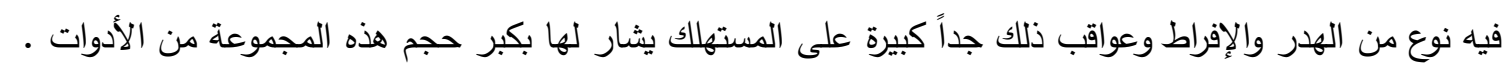
إنه استخدام ذكي وإبداعي من لان النحات حسن شريف الذي نقل مواد عمله من بيئة وظيفية استعمالية الى بيئة

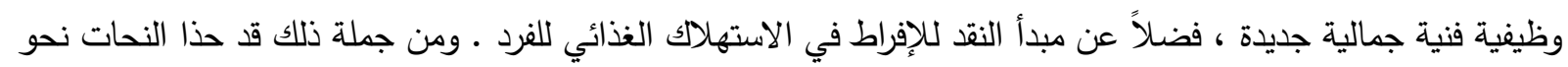

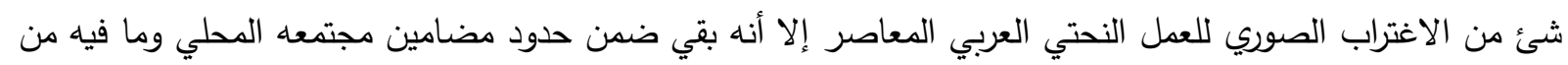
حالات معاشة .

\author{
نتائج البحث \\ من خلال ماتقدم من البحث تم التوصل الى النتائج الآتية :
}

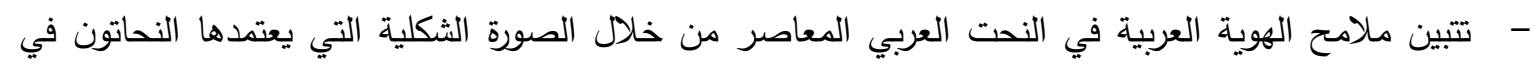
أعمالهم التي يستلهمون فيها الحرف العربي بتنوع صنوفه كما هو الحال في العمل رقم (1) والعمل رقم (3)، كون الحرف جزء من مقومات اللغة العربية وإعتماد ذلك في بيان ملامح الهوية في النحت العربي.

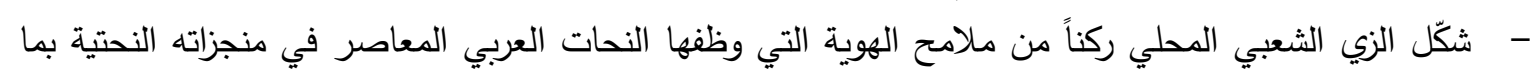
يعزز من هويته في ذلك ، كما هو في العمل رقم (2) . - - استلهام مفردات من الموروث الحضاري في العمل النحتي جزء مهم تتضح من خلاله ملامح الهوية العربية ،وهو

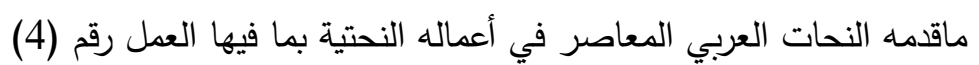

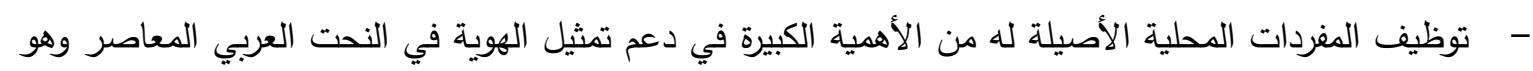

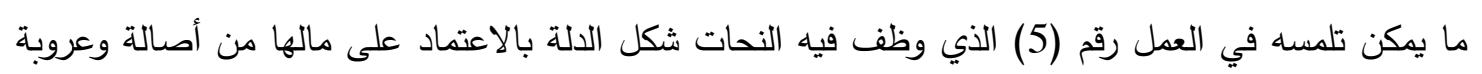
وكرم

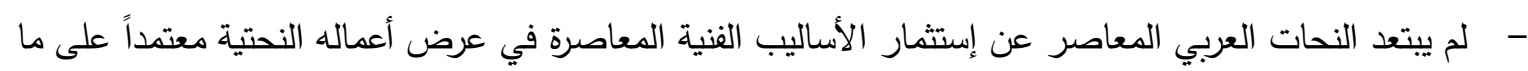
فيها من لغة فنية يمكن من خلالها مخاطبة الآخر كونها لغة عالمية ، يمكن أن يطرح من خلالها هويته المميزة بملامحها الظاهرية أو ذات الطابع النقدي كما في العمل رقم (6) الذي بانت فيه فلهن ملامح الاغتراب الفني الثكلي

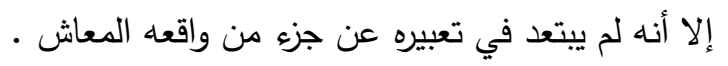




\section{التوصيات}

لمزيد من الفائدة المعرفية يوصي الباحث بالنقاط الآتية :

- - تكريس الجهود الفنية من قبل النحاتين المعاصرين العرب في التأكيد على الهوية العربية في منجزاتهم الفنية لما له من دور مهم في مجابهة الغزو الثقافي الذي تتعرض له الأمة العربية .

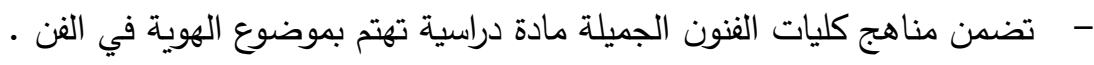

- - جمع الأعمال النحتية العربية المعاصرة في كتاب فني يعنى بموضوع الهوية في النحت العربي ، يكون مصدراً توثيقياً لهذه الأعمال أولاً ، ومصدراً لبيان مقومات هذه الهيه لهوية في النحت ثانياً. توجيه بحوث الدراسات العليا (الماجنتير والدكتوراه) لدراسة موضوع الهوية في النحت ، وفق الديات المنهج العلمي للبحوث الفنية . - - دعوة القائمين على المؤتمر الدولي (فن النحت والخزف والهوية العربية ) الى أن يكون مؤتمراً سنوياً لما فيه من

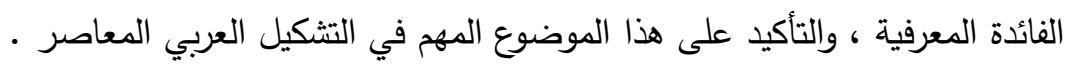
المصادر

1. أليكس ميكثللي : الهوية ، ترجمة : د.علي وطفة، دار الوسيم للطباعة ،دمثق،1993. 2. حسن حنفي حسين: الهوية ، المجلس الأعلى للثقافة ، القاهرة، 2012 ، 2012 3. لزهر مساعدية : نظرية الاغتراب من المنظورين العربي والغربي ، دار الخلدونية ، الجزائر،2013. 4. مجموعة مؤلفين :الهوية وقضاياها في الوعي العربي المعاصر ، مركز دراسات الوحدة العربية ، بيروت ، 2013. 5. محمود شاهين : الفن التشكيلي العربي المعاصر والتكنولوجيا،مجلة الحياة التشكيلية ،مجلة فصلية تعنى بفنون

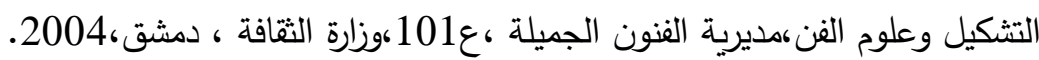
6. محمود شمال حسن:الثباب ومشكلة الاغتراب في المجتمع العربي ،دار الثؤون الثقافية العامة ، بغداد ، 2008. 7. مزيان وردية : الاغتراب الاجتماعي وتأثيره على الهوية الوطنية لاى الثباب الجزائري ، رسالة ماجستير غير منشورة

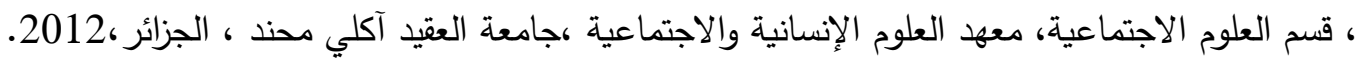

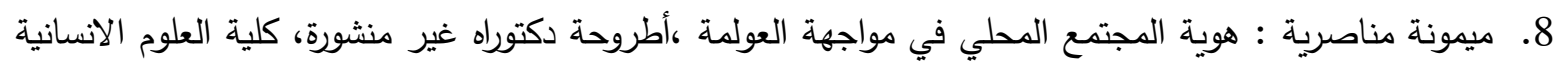
والاجتماعية ، جامعة محمد خيضر، الجزائر ، 2012.

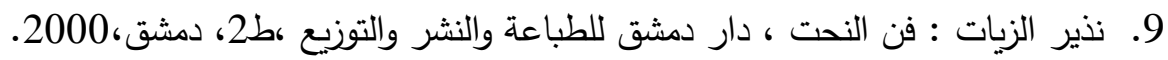

